\title{
Development and Application of Synthetic Hematite Reference Material for U-Pb Geochronology
}

Liam Courtney-Davies ${ }^{1}$, Cristiana Ciobanu ${ }^{2}$, Sarah Gilbert ${ }^{3}$, Simon Tapster ${ }^{4}$, Marcus Richardson ${ }^{5}$, Nigel Cook ${ }^{6}$, Max Verdugo-Ihl ${ }^{6}$, Benjamin Wade ${ }^{3}$, Kathy Ehrig ${ }^{7}$ and Daniel Condon ${ }^{4}$

${ }^{1}$ The University of Adelaide, Pert, Western Australia, Australia, ${ }^{2}$ The University of Adelaide, Australia, ${ }^{3}$ Adelaide Microscopy, Australia, ${ }^{4}$ British Geological Survey, United Kingdom, ${ }^{5}$ University of Adelaide, United States, ${ }^{6}$ University of Adelaide, Australia, ${ }^{7}$ BHP Olympic Dam, Australia

The common iron oxide hematite $\left(\alpha-\mathrm{Fe}_{2} \mathrm{O}_{3}\right)$ can incorporate significant concentrations of $U$ into its crystal structure and retain radiogenic Pb over geological time (Duff et al., 2002; Ciobanu et al., 2013). Hematite is a ubiquitous component of planetary crusts (e.g. ore deposits, banded iron formations, regolith), and represent a valuable geochronometer allowing direct constraints to be placed on the timing of mineral precipitation (e.g. Courtney-Davies et al., 2019a; Keyser et al., 2019). Development of the hematite mineral geochronometer is important because, unlike accessory minerals routinely used to track hydrothermal mineralization, hematite has been shown in certain cases to incorporate negligible common $\mathrm{Pb}$ and appears resistant to radiation damage accumulation (Courtney-Davies et al., 2020). Most hematite U-Pb dating studies have utilized laser ablation inductively coupled plasma mass spectrometry (LA-ICP-MS), due to its relatively high spatial resolution, speed and low cost. However, no suitable natural haematite reference material has been identified, necessitating use of a variety of primary and secondary zircon reference materials. Here, a hematite U-Pb reference material, named MRHFO, was synthesised and then characterised using LA-ICP-MS and isotope dilution-thermal ionization mass spectrometry (ID-TIMS), to test the materials homogeneity.

Synthetic $\alpha-\mathrm{Fe}_{2} \mathrm{O}_{3}$ co-doped with $\mathrm{U}$ and $\mathrm{Pb}$ was prepared from a solution of ferric nitrate precipitated with ammonia solution (Courtney-Davies et al. 2019b). This reaction produced a suspension of colloidal hydrated ferric oxide that was washed with water several times by decantation until it peptised. A doping solution of uranyl and lead nitrates was then added to adsorb the $\mathrm{U}$ and $\mathrm{Pb}$ onto the colloidal hydrated ferric oxide particles. After settling, the doped material was dried at $50{ }^{\circ} \mathrm{C}$ to produce solid chips, each several millimetres in thickness, followed by heating to $700{ }^{\circ} \mathrm{C}$. The material was held at $700{ }^{\circ} \mathrm{C}$ for $10 \mathrm{~h}$, after which it was furnace-cooled to ambient temperatures, resulting in conversion of doped hydrated ferric oxide to $\alpha-\mathrm{Fe}_{2} \mathrm{O}_{3}$.

Centimetre-scale chips of synthesised a- $\mathrm{Fe}_{2} \mathrm{O}_{3}$ were randomly microsampled via 'laser ablation-extraction' and analysed using ID-TIMS at the British Geological Survey. Reproducible U/Pb and $\mathrm{Pb} / \mathrm{Pb}$ ID-TIMS measurements were obtained across four separate chips $(n=13)$. Data obtained from MR-HFO is displayed in Figure 1.

Subsequently, an evaluation of the suitability of MR-HFO in constraining U-Pb data via LA-ICP-MS (performed at Adelaide Microscopy) was carried out using a selection of natural samples derived from iron oxide-Cu-Au systems, including Olympic Dam (Australia), Carajás (Brazil) and Mantoverde (Chile), which range from Cenozoic to Proterozoic in age. The MR-HFO normalised $\mathrm{U}-\mathrm{Pb}$ ratios were more concordant and ages more accurate versus the same LA-ICP-MS spot analyses normalised to zircon reference material, when compared with independently acquired ID-TIMS data from the same natural hematite grains (Figure 2). These results establish MR-HFO as a 
suitable reference material for LA-ICP-MS hematite U-Pb geochronology, and represent the first ever synthetic U$\mathrm{Pb}$ reference material (Courtney-Davies et al., 2021).

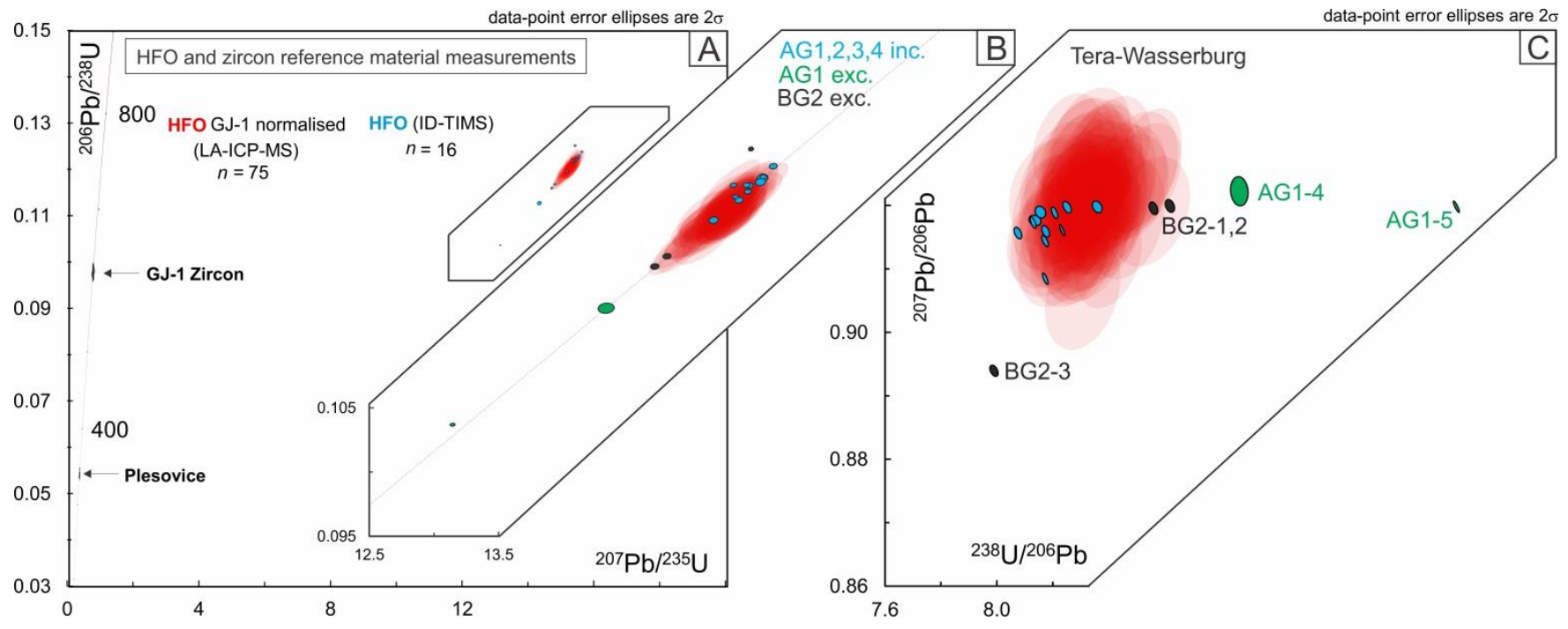

Figure 1. (A) Wetherill Diagram showing LA-ICP-MS measurements of secondary zircon reference materials (GJ1 and Plešovice) and MR-HFO (red ellipses) normalised to GJ-1 zircon. (B) inset of (A), displaying the ID-TIMS measurements of MR-HFO. Blue ID-TIMS ellipses represent analyses used for calibration of MR-HFO, green and blue ellipses were excluded analyses from more heterogeneous chips. (C) The same data displayed in (B) transformed into a Tera-Wasserburg diagram. Note the slight offset between ID-TIMS (blue) and GJ-1 (red) normalised LA-ICP-MS measurements of MR-HFO. 


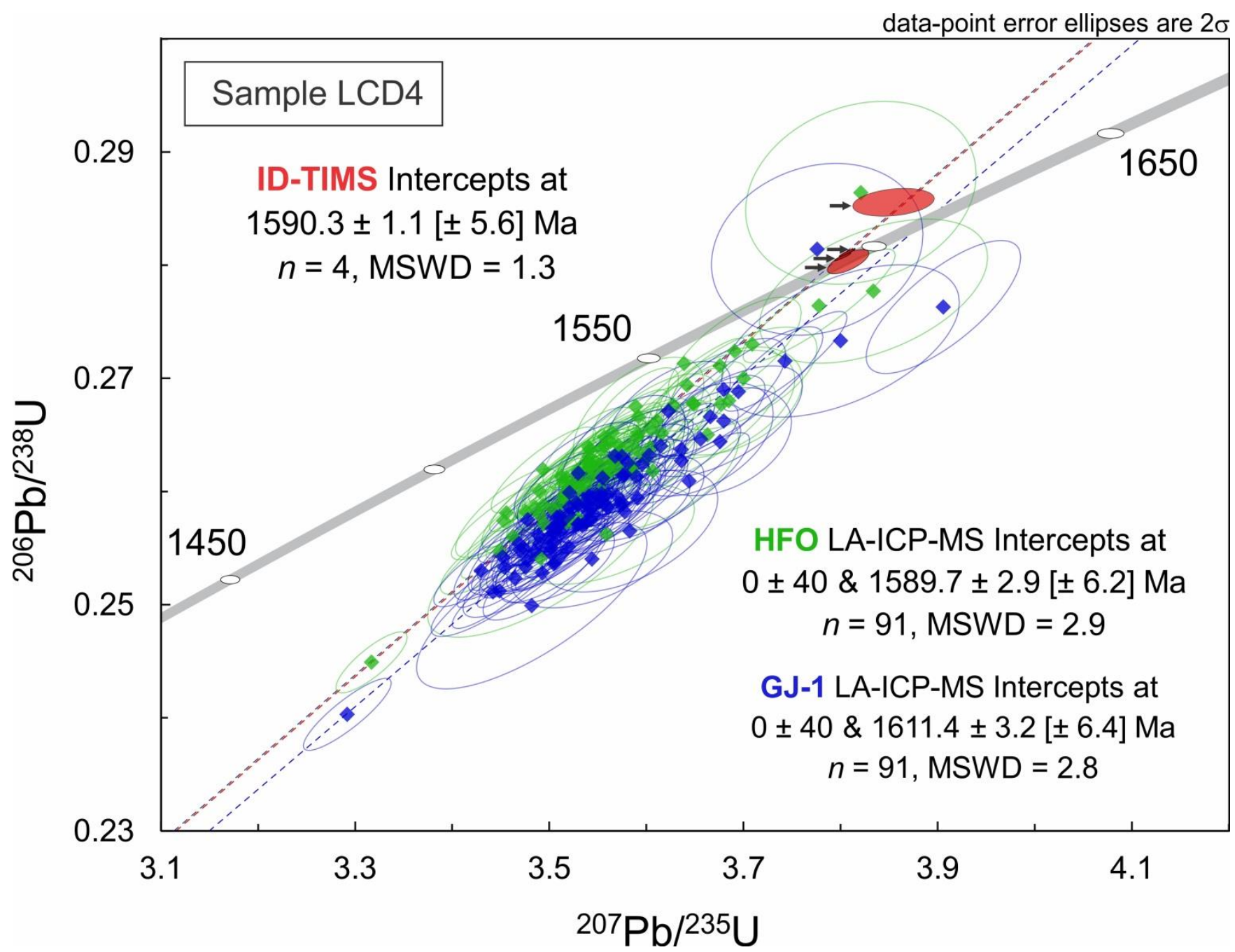

Figure 2. Wetherill diagram displaying a comparison of ID-TIMS data versus LA-ICP-MS data, which has been normalised using both MR-HFO (green ellipses) and GJ-1 zircon (blue ellipses). All ID-TIMS measurements and LA-ICP-MS spot analyses were obtained from the same grain of hematite at Olympic Dam. Note the improved accuracy of MR-HFO normalised data in terms of the upper intercept date versus GJ-1 normalised, when compared with the independent ID-TIMS intercept.

References

Ciobanu C.L., Wade B.P., Cook N.J., Schmidt M.A. and Giles D. (2013) Uranium-bearing hematite from the Olympic Dam $\mathrm{Cu}-\mathrm{U}-\mathrm{Au}$ deposit, South Australia: A geochemical tracer and reconnaissance $\mathrm{Pb}-\mathrm{Pb}$ geochronometer. Precambrian Research, 238, 129-147.

Courtney-Davies L., Tapster S.R., Ciobanu C.L., Cook N.J., Verdugo-Ihl M.R., Ehrig K.J., Kennedy A.K., Gilbert S.E., Condon D.J. and Wade B.P. (2019a) A multi-technique evaluation of hydrothermal hematite UPb isotope systematics: Implications for ore deposit geochronology. Chemical Geology, 513, 54-72.

Courtney-Davies L., Ciobanu C.L., Richardson M.W., Prosser N., Verdugo-Ihl M.R., Wade B.P., Gilbert S.E., Ehrig K. and Cook N.J. (2019b). Synthesis of U-Pb doped hematite using a hydrated ferric oxide approach. Journal of Crystal Growth, 513, 48-57.

Courtney-Davies L., Ciobanu C.L., Tapster S.R., Cook N.J., Ehrig K.J., Crowley J.L., Verdugo-Ihl M.R., Crowley J., Wade B.P. and Condon D.J. (2020) Opening the magmatic-hydrothermal window: High-precision U-Pb 
geochronology of the Mesoproterozoic Olympic dam Fe-oxide-Cu-U-Au-Ag deposit, South Australia. Economic Geology, 115 (8): 1855-1870.

Courtney-Davies, L., Gilbert, S.E., Ciobanu, C.L., Tapster, S.R., Richardson, M.W., Cook, N.J., Wade, B.P., Verdugo-Ihl, M.R., Ehrig, K. and Condon, D.J. (2021), A Synthetic Haematite Reference Material for LA-ICP-MS $\mathrm{U}-\mathrm{Pb}$ Geochronology and Application to Iron Oxide-Cu-Au Systems. Geostandards and Geoanalytical Research. https://doi.org/10.1111/ggr.12365.

Duff M.C., Coughlin J.U. and Hunter D.B. (2002) Uranium co-precipitation with iron oxide minerals. Geochimica et Cosmochimica Acta, 66, 3533-3547.

Keyser W., Ciobanu C.L., Cook N.J., Dmitrijeva M., Courtney-Davies L., Feltus H., Gilbert S., Johnson G. and Ehrig K. (2019) Iron-oxides constrain BIF evolution in terranes with protracted geological histories. The Iron Count prospect, Middleback Ranges, South Australia. Lithos, 324-325, 20-38. 